\title{
Appelrechters kunnen van elkaar leren
}

\author{
Prof. mr. A. Hammerstein*
}

\begin{abstract}
Inleiding
De devolutieve werking van het appel is de schrik van menig raadsheer. Ik heb ooit geschreven over het spook van de devolutieve werking, ${ }^{1}$ maar wellicht is zij te beter te vergelijken met een torpedo die wordt afgeschoten van Zijner Majesteits onderzeeër de Hoge Raad der Nederlanden. Zij veroorzaakt volkomen onverhoeds een midscheepse treffer, met als gevolg de roemloze ondergang van een met zorg gemaakt arrest. Soms raakt de onderzeeër zelf verstrikt in de netten van deze weerbarstige materie, zoals in de zaak Fafianie/KSN het geval lijkt te zijn. ${ }^{2}$ Daarover wil ik het vandaag niet hebben. De vraag blijft echter: hoe komt het toch dat het burgerlijk appelprocesrecht zo ingewikkeld is geworden dat het door Snijders ${ }^{3}$ precies op dit punt als een mandarijnenwetenschap is gekwalificeerd?
\end{abstract}

De voornaamste reden is naar mijn mening dat we in het algemeen geen hoger beroep willen dat louter en alleen een volledige herkansing is. Dat is in strijd met de proceseconomie. Dus komen er regels over drempels, grievenstelsel, incidenteel appel, berusting, wel of geen nieuwe feiten, gedekt verweer. En al die regels blijken uitzonderingen te hebben en nuanceringen. Dit alles gebeurt vanuit verschillende gezichtspunten over de functie van, toegang tot en inrichting van het hoger beroep. Wat de rechtsgebieden betreft, zien we soms harmonisatie en soms grote verschillen. Het civiele appelprocesrecht is in de loop der tijd gedeformaliseerd en juist mede daardoor ingewikkeld geworden. ${ }^{4}$ Het bestuursprocesrecht is bewust eenvoudig gehouden, maar neigt nu tot formalisering, zoals grieven en incidenteel appel, en wordt ook ingewikkelder. ${ }^{5} \mathrm{Ik}$ zal dit nader toelichten aan de hand van enkele onderwerpen. $^{6}$

Prof. mr. Hammerstein is raadsheer in buitengewone dienst Hoge Raad der Nederlanden.

1. Zie: B.T.M. van der Wiel, R.S. Meijer \& F.E. Vermeulen (red.), Uit de praktijk. Liber amicorum mr. P.J.M. von Schmidt auf Altenstadt, Den Haag: Boom Juridische uitgevers 2012, p. 113.

2. HR 30 maart 2012, NJ 2012/583. Daarover Asser Procesrecht/Bakels, Hammerstein \& Wesseling-van Gent, nr. 133; A.C. van Schaick, Tegenstrijdige beslissingen, NTBR 2013/1, p. 1 e.v.; B.T.M. van der Wiel, noot onder JBPr 2013/17.

3. Noot onder NJ 2005/282 (Utimaco).

4. Asser Procesrecht/Bakels, Hammerstein \& Wesseling-van Gent, nr. 3.

5. Zie R.J.N. Schlössels \& C.L.G.F.H. Albers, Het bestuursrechtelijk hoger beroep: schuivende panelen, in: P.H.P.H.M.C. van Kempen, C.J.M. Klaassen, R.J.N. Schlössels \& J.J. Dammingh (red.), Hoger beroep: renovatie en innovatie. Het appel in het burgerlijk, straf- en bestuursprocesrecht, (Serie Staat en Recht, deel 16), Deventer: Kluwer 2014. Aan deze Nijmeegse bundel was het symposium van 25 april 2014 gewijd. Ik spreek verder over de bundel Hoger beroep.

6. Zie ook A. Hol \& J. Verburg (red.), Innoverende Hoven. Agenda voor de appelrechtspraak 2020, Den Haag: Boom Juridische uitgevers 2014, met tal van aanbevelingen.
Enkele vergelijkingen

a. De rechtspolitieke wenselijkheid. Het hoger beroep kan qua omvang heel ruim zijn en heel beperkt. Meestal is hier de wetgever aan zet en soms de rechter. Uitsluiting is een zaak van de wetgever, maar de rechter kan met doorbrekingsgronden weer een opening maken. Het appel kan soms op grond van verdragsrecht niet uitgesloten worden, zoals in strafzaken, en soms gebeurt dat bij een fundamenteel recht als dat van eigendom wel, zoals in onteigeningszaken waar de rechtbanken in samenwerking met de Hoge Raad er wonderwel in slagen het appel overbodig te maken. Waarbij dan weer vreemd is dat na verwijzing de zaak wel naar een hof gaat. Soms ontstaat over uitsluiting van appel discussie, zoals nu al heel lang bij de ontbinding van de arbeidsovereenkomst. En soms weten we niet goed of er een voortbouwend appel mogelijk is, zoals in strafzaken. ${ }^{7}$ In het bestuursrecht speelt een rol dat er altijd een bezwarenprocedure aan de procedure bij de rechter is voorafgegaan. Dat kan een rechtvaardiging zijn voor beperkingen. In het bestuursrecht bestaat geen hoger beroep van voorlopige voorzieningen, in het civiele recht wel. Zijn deze verschillen gerechtvaardigd?

b. Het hoger beroep is verschillend ingericht. In het bestuursprocesrecht is het gericht tegen de uitspraak van de eerste rechter. Dan heeft het sterk het karakter van controle op die uitspraak. In het strafprocesrecht is het een vrijwel volledige tweede instantie. In het burgerlijk procesrecht is het een voortgezette instantie waarin niet het vonnis object van beoordeling is, maar de oorspronkelijke vordering zoals die in appel is gehandhaafd of gewijzigd. Als de controlefunctie overheerst, wordt het appel beperkt gehouden. Bij de herkansing juist niet.

c. Uit een oogpunt van doelmatig procederen is een herhaling van zetten niet aan te bevelen. Daarom zien we overal processuele stroomlijning gericht op het aanvoeren van bezwaren. Dat betekent in de eerste plaats een grievenstelsel, dat tegenwoordig eigenlijk een grondenstelsel zou moeten heten. De bestuursrechter beperkt zich tot een beoordeling van de gronden van het hoger beroep, maar het civiele procesrecht kent een tweede fase bij het slagen van een of meer grieven. Door het accent op de herkansingsfunctie zijn grieven daar tot verdriet van enkele schrijvers veranderd in gronden. Echte grieven passen meer bij de controlefunctie. In het civiele recht is de tijdigheid van grieven een bekend leerstuk dat recent door de Hoge Raad nog wat strakker is aangetrokken door con-

7. Zie J.M. Reijntjes, Eigen procesrecht voor de strafrechter in hoger beroep?, in de bundel Hoger beroep, p. 198. 
centratie van het debat in hoger beroep. Voor het bestuursrecht bepleiten Polak en De Poorter de introductie van een 'vriespunt' waarna het niet meer mogelijk is nieuwe grieven aan te voeren. ${ }^{8}$ Dus in wezen hetzelfde als in het civiele procesrecht de tardieve grieven. De devolutieve werking van het civiele hoger beroep gaat veel verder dan in het bestuursrecht. Opnieuw de toewijsbaarheid van de vordering beoordelen brengt met zich dat alle relevante stellingen opnieuw worden bekeken. Dat vergt een grondige bestudering van het dossier en een analyse van de grenzen van de rechtsstrijd. Blijkbaar hebben appelrechters daarvoor niet altijd voldoende tijd. Cassatieadvocaten en het parket bij de Hoge Raad nemen die tijd wel en daarom gaat het een enkele keer mis. Het is heel goed denkbaar om het systeem anders in te richten: dan moet de advocaat het werk doen door tegen alle nadelige beslissingen van de eerste rechter bezwaar te maken, waardoor het incidenteel appel veel vaker dan nu nodig is. De keuze is dus ook werkbesparing voor de appelrechter of meer rechtsbescherming in appel. Dat is ook de keuze die is gemaakt in de Agenda voor de appelrechtspraak 2020. Ik kom daarop terug aan het slot van mijn betoog.

d. Bij de herkansing ligt het mogen aanvoeren van nieuwe feiten en stellingen voor de hand, tot de grens van de goede procesorde. Polak en De Poorter pleiten in de bundel juist voor een beperking van het bestuursrechtelijk appel niet alleen door een grievenstelsel, maar ook door slechts in beperkte mate nieuwe feitelijke gronden en argumenten toe te laten. In hun visie moet in het appel het accent liggen op rechtseenheid en rechtsontwikkeling, terwijl in het civiele appelprocesrecht wordt gepleit voor een ruime mate van rechtsbescherming en verwezenlijken van de materiële gerechtigheid. Op die grond keert Valk zich juist tegen processuele beperkingen zoals die in de jurisprudentie van de Hoge Raad overigens slechts heel mild zijn te vinden. ${ }^{9}$ Ik sluit me in dit opzicht aan bij Polak en de Poorter ${ }^{10}$ die erop wijzen 'dat van partijen mag worden verwacht dat zij op verantwoorde wijze procederen'. Die maatstaf was ook al door het driemanschap voorgesteld in hun rapporten over een fundamentele herbezinning en werd toen nog niet algemeen omhelsd. ${ }^{11}$ Ik meen dat de ruime herkansingsfunctie inderdaad alleen te handhaven is als dat niet leidt tot een oeverloze procedure in hoger beroep.

e. Dan wat potjeslatijn: de beoordeling ex tunc of ex nunc? De bestuursrechter moet uitgaan van het besluit in primo. Dat beperkt zijn ruimte, maar inmiddels is daar een spectaculaire ontwikkeling aan de gang door de finale geschillenbeslechting, de bestuurlijke lus en zeer recent de judici-

8. C.J.A. de Poorter \& J.E.M. Polak, Naar een evenwichtiger bestuursrechtelijk appel, in de bundel Hoger beroep, p. 151.

9. W.L. Valk, De mondelinge behandeling in het civiele hoger beroep, in de bundel Hoge beroep, p. 161 e.v.

10. Valk, p. 141.

11. W.D.H. Asser, H.A. Groen, J.B.M. Vranken, m.m.v. I.N. Tzankova, Uitgebalanceerd. Eindrapport fundamentele herbezinning Nederlands burgerlijk procesrecht, Den Haag: Boom Juridische uitgevers 2006. ele lus. De bestuursrechtelijke procedure groeit naar een contradictoire procedure toe en dat heeft ook consequenties voor het appel. In het burgerlijk procesrecht moet de rechter in appel oordelen 'naar de toestand zoals die zich voordoet ten tijde van zijn beslissing (NJ 1993/714)'. Nieuwe ontwikkelingen worden dus meegenomen, maar anderzijds betekent de substantiëringsplicht dat zo veel mogelijk al in eerste aanleg wordt aangevoerd en stelt de concentratie van het debat ook grenzen. In het strafrecht lijkt mij de actualiteit van de beoordeling aan de hand van alle bekende feiten van groter belang dan de beoordeling van de juistheid van het vonnis van de eerste rechter.

f. Hoger beroep is een kostbaar en schaars goed. Daaruit volgt dat aan appellanten eisen gesteld mogen worden wat de wijze van procederen betreft, in het bijzonder wat het belang van het appel betreft. Als niet aan die eis wordt voldaan, voel ik veel voor het voorstel van Polak en De Poorter om het hoger beroep af te doen met een verkorte motivering. Die is in het civiele appelrecht nu mogelijk als appellant volstaat met een herhaling van zijn standpunt, maar door het ruime gebruik van de herkansingsfunctie komt dit zelden voor. Daarom zou ik het voor de stroomlijning goed vinden als alle appelrechters bij een kennelijk ongegrond beroep mogen volstaan met die constatering. Het appel zal naar mijn mening altijd de functie van rechtsbescherming inhouden, maar die rechtsbescherming moet wel een voldoende belang hebben. Waarom zou ook in bagatelzaken appel mogelijk moeten zijn?

g. Uitsluiting van hoger beroep in verband met de aard van de zaak moet overwogen worden. Heeft de appelrechter een taak bij omgangsregelingen die een beperkte houdbaarheidsduur hebben? Moet de bestuursrechter oordelen over alle beslissingen van de Belastingdienst Toeslagen (dus ook over uitstel van betaling)? Waarom zouden de Hoge Raad en de appelrechter moeten oordelen over schuldsaneringen, als de beoordeling daarvan vrijwel altijd van feitelijke aard is? Is een boete van minder dan $€ 500$ de moeite waard om nog eens te laten beoordelen? Blijkbaar is ook het verlofstelsel op dit punt geen goede oplossing gebleken.

h. Rechtseenheid en rechtsvorming. Als ik het goed zie, zit tussen de drie rechtsgebieden een tamelijk wezenlijk verschil in hoger beroep. De Afdeling, de Centrale Raad van Beroep en het College van Beroep voor het bedrijfsleven zijn vooralsnog ook hoogste rechters. $\mathrm{Zij}$ hebben op hun gebied het laatste woord en dan zijn vragen van rechtseenheid extra belangrijk. Omdat zij anders dan de Hoge Raad ook feitenrechters zijn, gaan deze rechters echter anders om met rechtseenheid en rechtsontwikkeling. De casuistiek blijft een belangrijke rol spelen en feitelijke beoordeling leent zich in veel gevallen niet goed voor duidelijke rechtsvorming. Ik lees bij Schlössels en Albers het volgende: 'Volgens ons kan een (beperkt) cassatieberoep niet worden gemist, al was het maar om het hoger beroep tot zijn recht te laten komen. Hoewel feitenrechtspraak en rechtsvorming vruchtbaar kunnen samengaan (en soms 
moeten samengaan) biedt een zekere scheiding van taken in dit verband voordelen.' ${ }^{2}$ Dat is een andere benadering dan die van Polak en De Poorter. Art. 80a is nooit bedoeld geweest om de taak van de hoven te veranderen, maar de Hoge Raad heeft beleidsruimte als het gaat om de rechtsbescherming. Veel richtinggevende jurisprudentie komt van de appelrechtspraak, hetzij doordat daar de juiste beslissing is gevallen hetzij doordat deze de opstap vormt naar een cassatieberoep. Wat ik voorzie, is dat de taak van de Hoge Raad, en de hoogste rechters, vooral komt te liggen bij zaken met rechtspolitieke keuzen, met name als het gaat om de handhaving van fundamentele rechten en Europeesrechtelijke en internationale dimensies. Voorbeelden daarvan zijn de SGP-zaak en de recente zaak Martijn. Ik voorzie daarnaast een groei van het aantal prejudiciële vragen. Bijna alle vragen zijn afkomstig van de eerste rechter, maar onlangs zijn er twee vragen van een hof gekomen. Waarom lieten de hoven zo lang verstek gaan? En ten slotte is er de vervaging van de grenzen tussen de rechtsgebieden. Vooral door Europeesrechtelijke regelgeving zijn de grenzen tussen privaatrecht en publiekrecht aan het verdwijnen. ${ }^{13}$ De bestuursrechter komt op het terrein van de civiele rechter en de strafrechter. De samenwerking tussen alle rechters en dan vooral de appelrechters en de Hoge Raad zal dus moeten toenemen. Waarom zou de Afdeling geen prejudiciële vragen kunnen stellen aan de Hoge Raad en vice versa? Of is dat een te wild idee?

i. De kosten beginnen een steeds grotere rol te spelen. Hoger beroep in civiele zaken wordt daardoor voor velen onbereikbaar. Een verhoging van de griffierechten kan ernstige gevolgen hebben. Het is net als bij accijns op benzine in de grensstreek. De overheid bespaart op de kosten van de appelinstanties, maar vergeet dat het appel voor de rechtspraak ook een besparing oplevert. Rechters die weten dat er nog een mogelijkheid bestaat dat opnieuw naar de zaak gekeken wordt, kunnen het zich permitteren in bepaalde zaken wat minder diep te gaan en eerder te beslissen. Er is immers een achtervanger. Soms weet de eerste rechter al dat de zaak toch doorgaat in appel en dat kan meebrengen dat er wat minder tijd in de eerste aanleg wordt gestoken. De appelrechter die de Hoge Raad achter zich weet mag dat niet. Cassatie is te kostbaar en te bewerkelijk om als noodopvang te dienen. Appelrechters moeten hun werk grondig doen. Dan kan het nog verkeerd gaan, maar de cassatierechter moet qua rechtsbescherming niet de belangrijkste taak hebben.

12. Bundel Hoger beroep, p. 61. Vgl. ook mijn opstel De Afdeling bestuursrechtspraak als rechtsvormer, in: H.D. Tjeenk Willink e.a. (red.), De Raad van State in perspectief, Den Haag: Boom Juridische uitgevers 2011, p. 325 e.v.

13. Kortheidshalve verwijs ik naar W. van Gerven \& S. Lierman, Algemeen Deel. Veertig jaar later. Privaat- en publiekrecht in een meergelaagd kader van regelgeving, rechtsvorming en regeltoepassing, Mechelen: Kluwer 2010. j. Ten slotte het belang van het appel gemeten aan de cijfers (van 2012). ${ }^{14}$ In de civiele procedure bedragen de appelpercentages 22 procent voor de handelszaken, 8 procent voor de kantonzaken en 4 procent voor de kantonzaken. In strafzaken die gaan over misdrijven: voor de politierechter 12 procent, de kantonrechter 8 procent en de meervoudige kamer 38 procent. In zaken over rijksbelastingen 38 procent, vreemdelingen 50 procent en bestuur in het algemeen 22 procent. De maatschappelijke behoefte aan appel is hiermee voldoende onderstreept. In verhouding tot de kosten is er nauwelijks reden het hoger beroep weg te bezuinigen. Vanuit een principieel standpunt over kwaliteit en legitimiteit helemaal niet. Rechtseenheid en rechtsuniformiteit kunnen alleen met appel bereikt worden. Rechtsvorming geschiedt door alle rechters, maar hier is een herkenbare hoogste rechter nodig om echt richtinggevend te kunnen zijn.

k. Gelukkig is er ook een ontwikkeling te zien dat tijdigheid en actualiteit veel aandacht krijgen. De Afdeling stuurt daarop al lang met succes. In de gewone rechtspraak is tijdigheid in appel inmiddels een erkende kwaliteitseis, al begrijp ik nog steeds niet waarom de procedure vaak toch nog vrij lang duurt. In de agenda voor de appelrechtspraak 2020 komt tijdigheid op plaats 6 in plaats van op plaats 1 . Uit de kengetallen blijkt dat de appelrechters de norm voor tijdigheid in 2012 gemiddeld slechts met 15 procent hebben gehaald, met als uitschieter het Hof ArnhemLeeuwarden dat 31 procent van de norm haalde.

\section{Aanbevelingen}

Het wordt tijd voor een aantal aanbevelingen.

Mijn eerste aanbeveling is dan ook, in aansluiting op eerdere oproepen, dat de appelrechters goed contact moeten houden met de eerste aanleg. Door stelselmatige uitwisseling van informatie en afstemming van beleid, kunnen vele fricties en misverstanden worden voorkomen. Ik wijs erop dat de Hoge Raad als een van de belangrijkste doelstellingen in zijn strategische agenda ${ }^{15}$ het contact met de feitenrechter heeft opgenomen. De Afdeling is als ik het goed zie verder dan de gewone rechtspraak met het geven van voorlichtingsbijeenkomsten en onderhouden van contacten. Tussen de hoogste bestuursrechters bestaat een overleg dat buitengewoon vruchtbaar is geweest in de afgelopen jaren omdat het gelukt is elkaar te vinden in plaats van de eigen positie te verdedigen. In de Agenda heet dit alles systeemoverleg.

Mijn tweede aanbeveling houdt in dat we moeten proberen zaken uit de appelrechtspraak weg te houden die daar werkelijk niet thuis horen, en omgekeerd ook voorkomen dat de rechtspraak terrein verliest waar het juist een goede taak heeft te vervullen. Er bestaan veel minkukelproblemen waarvoor de rechterlijke tussenkomst te duur en te ingewikkeld is. Rechterlijke capaciteit inzetten voor het oplossen van omgangsregelingen die niet tot stand komen door onverantwoordelijk gedrag

14. Ontleend aan Rechtspleging Civiel en Bestuur 2012 en aan gegevens die ik kreeg van de Raad voor de rechtspraak.

15. Niet gepubliceerd, maar wel besproken met de appelcolleges. 
van de ouders of van een van hen, is niet zinvol. De rechter moet er alleen aan te pas komen als niets anders meer helpt. De Afdeling wordt overbelast met zaken over zorg- en huurtoeslagen die best belangrijk zijn maar ook anders kunnen worden opgelost dan procederen in twee instanties na een bezwaarprocedure. De strafrechtspraak heeft ook te lijden onder vervolgingen die beter niet hadden kunnen plaatsvinden. Ik vind het prettig te weten dat 'mierenneuker' onder bepaalde omstandigheden wel en onder andere omstandigheden geen belediging in de zin van art. 266 Sr oplevert, ${ }^{16}$ maar $\mathrm{ik}$ had liever gezien dat daarover geen procedure in drie instanties was gevoerd, en dat nog wel voor de tweede keer. Ik hoor echter tegelijkertijd geluiden dat juist in de strafrechtspleging een grote verschuiving gaande is waardoor de strafrechters plaats moeten maken voor afdoening door het $\mathrm{OM}$ en ik heb geconstateerd dat veel strafrecht al is verplaatst naar het bestuursrecht. Wordt de strafrechter gemarginaliseerd?

Mijn derde aanbeveling is een verwijzing naar het rapport van de Commissie kernwaarden appelrechtspraak ${ }^{17}$ waarin tientallen voorstellen zijn opgenomen voor best practice. De appelrechtspraak heeft een voorbeeldfunctie en moet haar zaken volledig op orde hebben. Ook appelrechters begrijpen dat de bomen niet meer tot in de hemel groeien. Praat daarom liever niet over geld, maar over kwaliteit. Praat liever niet over werkdruk, maar over slimme oplossingen. Ruim achterstanden op en zoek naar werkmethoden die effectief zijn. Ga op zoek naar de bleeders: elke organisatie kent onvolkomenheden die leiden tot nodeloos capaciteitsverlies. Ik durf het ook wel iets harder te zeggen. Het wordt hoog tijd dat in plaats van praten over innoveren de tijd wordt besteed aan echte en kansrijke innovaties. Ik denk dat we dan moeten denken aan de volgende onderwerpen.

i. Concentratie en specialisatie. Er gaat veel tijd en kwaliteit verloren met onvoldoende deskundigheid. Organiseer vooral in appel de rechtspraak zo dat ervaren en goed geschoolde rechters snel en effectief kunnen werken. Dat betekent dat het algemeen belang boven dat van de individuele rechter gaat. Wisseling van kamer of sector omwille van de afwisseling mag niet.

ii. Houdt kennis en expertise vast en maakt die toegankelijk. Wat mij betreft kan de gewone rechtspraak mede in de leer gaan bij de Afdeling.

iii. Zorg voor een goed intern overleg dat de eenheid van rechtspraak waarborgt en dat ertoe bijdraagt dat de appelrechter zijn taak op het gebied van de rechtseenheid goed vervult.

iv. Zorg dat het werk op de juiste plaats wordt gedaan, dus zo laag mogelijk in de organisatie.

v. Zorg voor een optimale communicatie naar binnen en naar buiten.

vi. Maak bespreekbaar en meetbaar wat je onder kwaliteit verstaat.

vii. Besteed geen tijd aan zaken die er niet toe doen.

16. HR 17 december 2013, NJ 2014/181 m.nt. N. Keijzer.

17. Te vinden op de website van de Raad voor de rechtspraak. viii. In bepaalde gevallen kan best volstaan worden met enkelvoudige rechtspraak in appel, maar nooit in zaken die ertoe doen. ${ }^{18}$

ix. Maak optimaal gebruik van de mogelijkheden van digitaliseren en andere ict-mogelijkheden.

Mijn vierde aanbeveling is dat alle appelrechters verplicht het boek Professionals under Pressure lezen. ${ }^{19}$ Daarmee winnen we erg veel tijd die nu besteed wordt aan klagen over management en over de Raad voor de rechtspraak en de politiek die allemaal niets zouden begrijpen van de noden van de gewone rechter. Met het laatste ben ik het overigens wel een beetje eens, maar het geldt omgekeerd ook en het is van alledag. We zullen dus wel veel tijd moeten besteden aan voorlichting en uitleg. Het belang van de rechtspraak is groot en veel groter dan het belang van de individuele rechtsbescherming. We moeten zeker op onze hoede zijn voor afbraak van de rechtsstaat, maar ik weet uit eigen wetenschap dat die zorg ook bij de Raad en bij het ministerie bestaat. Op dit punt is er dus alle reden samen op te trekken in plaats van elkaar te wantrouwen. De chef van een driesterrenrestaurant zei onlangs in een interview: praat alleen over kwaliteit en niet over de prijs want die twee dingen hebben niets met elkaar te maken. Ik weet dat dit een riskant voorbeeld is, want rechters komen vermoedelijk niet vaak in dergelijke restaurants. Bovendien las ik bij Reijntjes $^{20}$ het volgende: 'De hoven zijn wel eens vergeleken met restaurants waar men doorgaans heel redelijk eet, maar met weinig gemak en tegen een te hoge prijs.' Dit is nog een heel vriendelijke vorm van kritiek. Wat daarvan zij, het is erg kortzichtig van de politiek om griffierechten in appel en in cassatie te verhogen. Dat past bij het profijtbeginsel, maar vergeten wordt dat appel en cassatie bijdragen aan de rechtsontwikkeling en aan de kwaliteit van de rechtspraak in het algemeen en aan het vertrouwen in de rechtspraak, mits de kwaliteit van die rechtspraak onbetwist hoog is. Het werd onlangs aldus verwoord: ${ }^{21}$

'Het feit dat rechtzoekenden meerdere kansen krijgen om hun recht te halen, waarbij "hogere" rechters een check vormen op de kwaliteit van het werk van "lagere" rechters is een van de absolute pijlers van de legitimiteit van de rechtspraak. Het gezag van de hoogste rechtscolleges - in het bijzonder de Hoge Raad - is groot, zowel binnen de rechtspraak als daarbuiten. Het gaat hierbij niet om een instantie die zich sterk heeft laten leiden door noties van tijdigheid, efficiëntie en maatschappelijke responsiviteit. Haar gezag berust juist op afstandelijkheid, juridische kwaliteit en wijsheid in de oordeelsvorming.'

18. Zie over dit onderwerp het opstel van J.J. Dammingh in de bundel Hoger beroep, p. 173 e.v.

19. Redactie M. Noordegraaf \& B. Steyn, Amsterdam: AUP 2013.

20. Reijntjes, bundel Hoger beroep, p. 188.

21. P. Frissen e.a., Governance in de rechtspraak (Research Memoranda 2014, nr. 1), Den Haag: Raad voor de rechtspraak 2014, p. 32. 
Ik zou graag zien dat deze functie, legitimiteit door bewaking van hoge kwaliteit, meer aandacht krijgt. Wat ik dan weer opmerkelijk vind, is dat bij het project inzake de toetsing van de kwaliteit van vonnissen ${ }^{22}$ sommigen menen dat deze vorm van kwaliteitstoetsing niet door de beugel kan. Ik ben lid van de stuurgroep die dit plan al jaren in praktijk tracht te brengen en ik ben er zeker van dat in deze groep geen uilskuikens zitten, al zal dit woord in dit verband niet toelaatbaar kunnen zijn. Zouden hier niet een beetje meer durf en wijsheid mogelijk zijn?

Mijn vijfde aanbeveling houdt in dat ook in appel de regie bij de rechter moet liggen. Iemand moet zorgen dat de procedures goed gaan, dat de ketenafstemming in orde is, dat de dingen die moeten gebeuren tijdig en goed gaan en dat de appelrechter kan beslissen op basis van een behoorlijk voorbereid dossier. Maak korte metten met partijen die alleen maar problemen over de schutting gooien en wijs erop dat alle procespartijen, inclusief het $\mathrm{OM}$ en het openbaar bestuur, de verplichting hebben behoorlijk en verantwoordelijk te procederen. De rechter kan dat alleen met gezag doen als zijn eigen zaken op orde zijn. Het is mogelijk dat de appelrechter iets meer mogelijkheden moet hebben om beroepen die kennelijk ongegrond zijn op een eenvoudige manier af te doen. De Afdeling gebruikt bij pure herhaling van zetten een verkorte motivering.

Mijn zesde aanbeveling is goed te onderkennen dat de kwaliteit van de appelrechtspraak voor 90 procent afhangt van de kwaliteit van de mensen en niet van het systeem. Men zegt dat mensen ofwel denken in systemen of in menselijke competenties. Voor het onderwerp van vandaag zou dit onderscheid vertaald kunnen worden in: moeten we sleutelen aan de inrichting of moeten we de cultuur veranderen? Ik denk: noblesse oblige. Appelrechtspraak heeft een voorbeeldfunctie.

\section{Slot}

Aan het slot van dit verhaal kom ik dan toch weer terug bij de devolutieve werking. In 1990 wees Bakels ${ }^{23}$ erop dat tussen de positie van appellant en verweerder - ik gebruik de termen van de nieuwe wetgeving - een onevenwichtigheid bestaat. Ik heb dat standpunt toen bestreden. In het Asser-deel Hoger beroep dat wij samen met collega Wesseling-van Gent hebben geschreven, hebben wij samen geprobeerd duidelijk te maken dat de devolutieve werking een proceseconomisch wonder is. In de Nijmeegse bundel schrijft Willemsen over dit onderwerp. ${ }^{24} \mathrm{Zij}$ vraagt zich af waarom de lijn die in het bestuursprocesrecht wordt gevolgd niet in het civiele procesrecht wordt toegepast. Dat zou onmiddellijk het probleem oplossen dat geïntimeerde van rechtswege aanspraak heeft op een volle- dige tweede fase. $\mathrm{Na}$ een kwart eeuw is er dus nog niets veranderd. Er is een probleem dat in mijn ogen niet bestaat, maar toch een probleem is. De devolutieve werking is dus toch een spook. Ik kies daarom alsnog met haar voor de oplossing die advocaat-generaal Wattel heeft voorgesteld en die door de belastingkamer van de Hoge Raad is aanvaard. Een polderoplossing: geen noodzaak van incidenteel appel, maar wel uitdrukkelijk handhaven van verworpen stellingen. Het heeft geen zin principieel te zijn, als dat onpraktisch blijkt. De Nijmeegse bundel heeft dus wat mij betreft reeds succes gehad.

22. Rechtspraakbrede toetsing civiele vonnissen, de meest gestelde vragen, Trema april 2014, p. 121 e.v.

23. F.B. Bakels, Enkele processuele onevenwichtigheden in de rechtspraak over hoger beroep in burgerlijke zaken, WPNR (1990) 5951, p. 145 e.v. waarop ik heb gereageerd in mijn bijdrage Hoger beroep in civiele zaken, in: G.J.M. Corstens e.a. (red.), Met hoofd en hart (Leytenbundel), Zwolle: Tjeenk Willink 1991, p. 301 e.v.

24. P.A. Willemsen, De toegang tot het bestuursrechtelijk hoger beroep gewogen, in de bundel Hoger beroep, p. 107 e.v. 